\title{
Disappearing Bone Disease with Disappearing Spleen!
}

\author{
John BM${ }^{1}$, Singh $\mathbf{D}^{2}$ \\ ${ }^{1}$ Dr. BM John, MD. Classified Specialist (Pediatrics), ${ }^{2}$ Dr Daljit Singh, MD, DM (Neonatology), Professor and Head \\ of Department of Pediatrics. Command Hospital (Air Force), Bangalore, India.
}

Address for Correspondence: E-mail: drbmj1972@yahoo.com

\begin{abstract}
A 6-year-old girl who reported for pain abdomen was incidentally detected to have multiple osteolytic lesions on X-ray. She was diagnosed as a case of Gorham's disease following confirmation with histopathology and kept on close follow-up. She was admitted again after 2 years for fever and investigations revealed an absent spleen apart from multicentric osteolytic lesions. This is the first case reported of a child with Gorham's disease who has had an auto-splenectomy on follow-up.
\end{abstract}

Key words: Gorham's disease (disappearing bone disease), osteolytic lesions, spleen.

\section{Introduction}

$\mathrm{G}$ orham's disease is a rare disorder characterized by proliferation of vascular or lymphatic channels that result in destruction and resorption of osseous matrix with gradual disappearance of bone tissue. The disease was first described by Gorham and colleagues (1954) and by Gorham and Stout (1955). The precise etiology of Gorham's disease continues to be poorly understood. ${ }^{1,2}$ We report the first child in literature with multicentric Gorham's disease undergoing autosplenectomy.

\section{Case Report}

A 6-year-old girlborn out of a non-consanguineous marriage presented to us with pain abdomen. This child had a chylothorax (left sided) in neonatal period, which was drained, with a subsequent normal course on follow-up. The old medical documents also revealed that the elder sister (Fig 1-B: Recent photograph showing significant short stature as opposed to the reported younger sibling) was a diagnosed case of osteogenesis imperfecta (Type 1) which we confirmed. Examination revealed a healthy child with normal stature (Fig 1-A showing the recent photograph) (both the weight and height being between $50^{\text {th }}-75^{\text {th }}$ centile). There were no significant findings on systemic examination. A plane $\mathrm{X}$-ray abdomen showed osteolytic lesions in lumbar spine. On skeletal survey multiple osteolytic lesions of the bone involving the axial and appendicular skeleton were detected which were also confirmed later with a MRI (Fig 2A and B). The routine biochemical investigations including alkaline phosphatase were normal. Radioisotope bone scan studies were also normal. The pain abdomen subsided with conservative treatment. The histopathological examination of the osteolytic lesion from left humerus revealed proliferating lymphatic tissue. Based on the presence of multiple osteolytic lesions, a history of chylous pleural effusion in neonatal period and a classical histologic appearance, a diagnosis of Gorham's disease was made. The child was put on alendronate (bisphosphonate) and kept on follow-up. She was again admitted at the age of eight years for a febrile episode. A USG abdomen revealed an absent spleen (spleen was present on USG \& CT scan done at previous admission) which was reconfirmed with a MRI abdomen (Fig 3A and B) and a sulfur colloid radionuclide scan. The hemoglobin electrophoresis and a screening with ANA and APLA done following the knowledge of an absent spleen, was normal. She was discharged on penicillin prophylaxis after pneumococcal and meningococcal vaccination and kept on close follow-up. She has been asymptomatic as of last review (Fig 1A). 


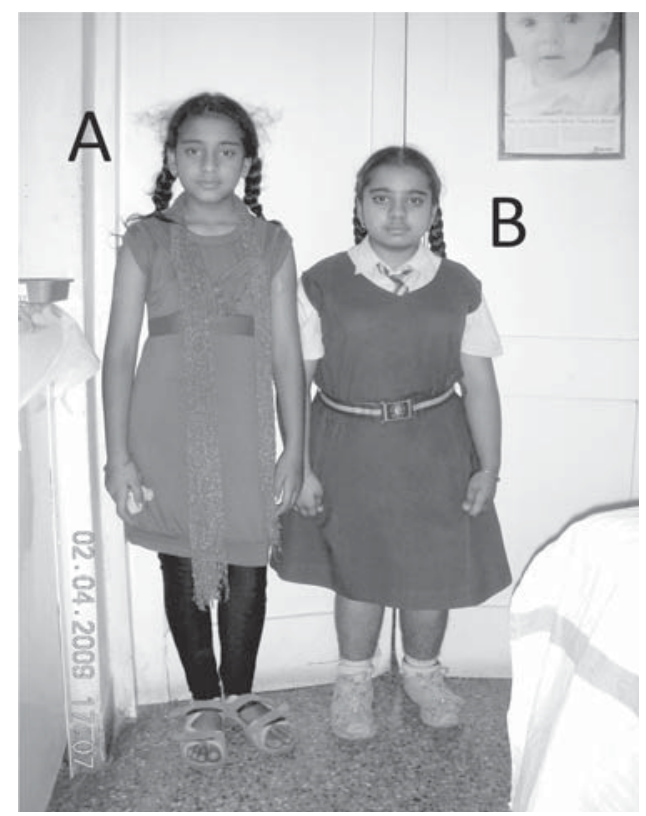

Fig 1A: Recent photograph of the child (now 9years old) with Gorham's disease. B: Photograph of the elder sister (13 years old) with Osteogenesis imperfecta (I).

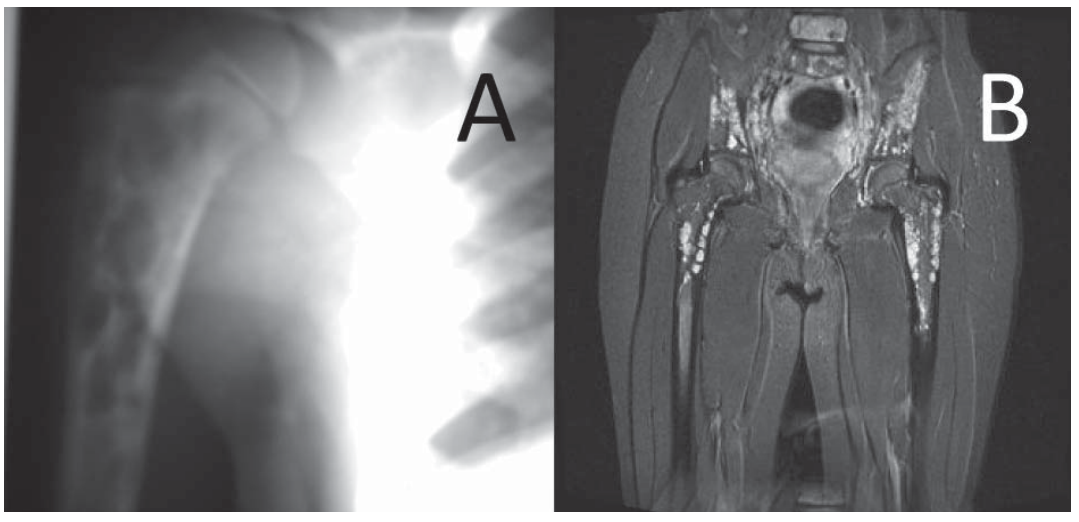

Fig 2A: Radiograph of shoulder showing multiple lytic lesions in the proximal humerus. B: Fat saturated T2W coronal MRI showing multiple lesions in the proximal femur, iliac bone and lumbosacral vertebra

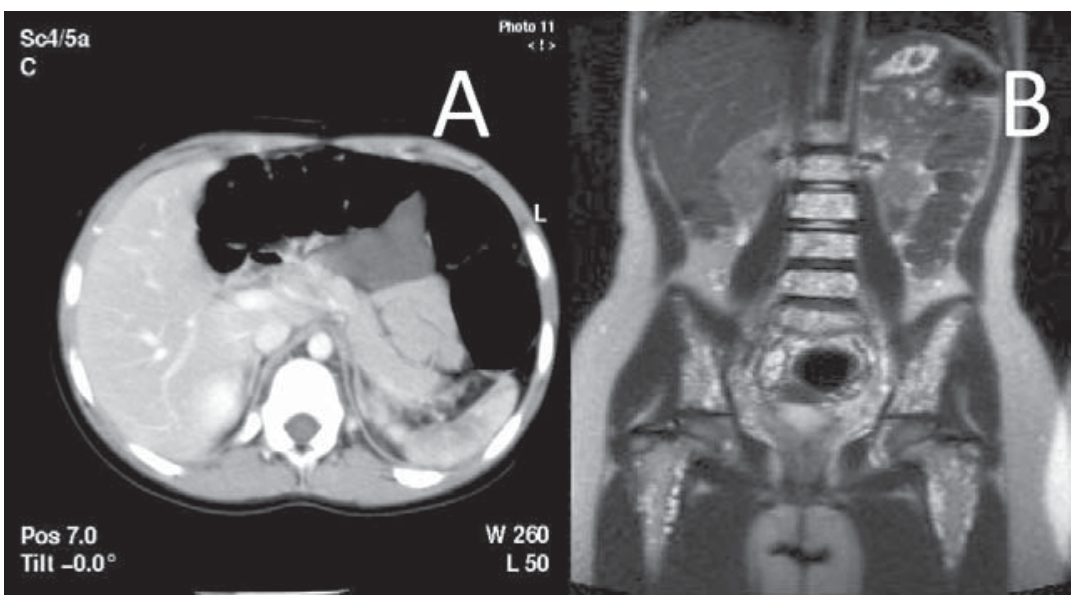

Fig 3A: Axial CECT of abdomen (2 years back) is showing the presence of spleen. B: Gradient T2W coronal image of abdomen and pelvis (present) showing absent spleen and multiple lesions in the vertebra, pelvic bone and femur. 


\section{Discussion}

The clinical presentation of Gorham's disease is variable and depends on the site of involvement. It often takes many months or years before the offending lesion is correctly diagnosed. A high index of clinical suspicion is needed to arrive at an early, accurate diagnosis. No familial predisposition has been found. The process may affect the appendicular or the axial skeleton. The shoulder and the pelvis are the most common sites of involvement ${ }^{2,3}$. Disease of the ribs, scapula, or thoracic vertebrae may lead to the development of chylothorax from direct extension of lymphangiectasia into the pleural cavity or via invasion of the thoracic duct ${ }^{4}$.

The patients may present with pain of the affected bone, fractures and rarely with chylous pericardial and pleural effusions ${ }^{2,4}$. Although the degree of osseous deformity in patients with Gorham's disease may become severe, serious complications are infrequent. Paraplegia related to spinal cord involvement may occur in patients who have involvement of vertebrae with resultant osteolysis 5 . Thoracic cage, pulmonary, or pleural involvement can lead to compromise of respiratory function and death can ensue ${ }^{6}$.

The etiology and pathophysiology of this poorly understood disease remains undetermined. The pathological process is the replacement of normal bone by an aggressively expanding but nonneoplastic vascular tissue similar to a hemangioma or lymphangioma. Histologically, involved bones show a non-malignant proliferation of thin-walled vessels; the proliferative vessels may be capillary, sinusoidal or cavernous.

Gorham and Stoutmaintained that activehyperemia, changes in local $\mathrm{pH}$, and mechanical forces promote bone resorption following some vascular derangement or diffuse hemangiomatosis. They hypothesized that trauma may trigger the process by stimulating the production of vascular granulation tissue, and that "osteoclastosis" is not necessary ${ }^{2,7}$. In contrast, Devlin and colleagues have suggested that bone resorption in patients with Gorham's disease is due to enhanced osteoclast activity, and that interleukin-6 (IL-6) may play a role in the increased resorption of bone ${ }^{8}$.

A variety of imaging methods can be used in evaluating patients suspected of having Gorham's disease. Plain radiographs, radioisotope bone scans, computed tomography (CT), and magnetic resonance imaging (MRI) have all been used in such evaluations? . During the initial stage of the lesion, radiolucent foci appear in the intramedullary or subcortical regions, resembling findings seen in patchy osteoporosis. Subsequently, slowly progressive atrophy, dissolution, fracture, fragmentation, and disappearance of a portion of the bone occurs with tapering or "pointing" of the remaining osseous tissue. The disease process can extend to contiguous bones; the intervening joints afford no protection to extension of the disease (10). The degree of osseous destruction generally increases over a period of years and may, eventually, stabilize spontaneously. Radioisotope bone scan findings have been variable. T1-weighted-spin echo MRI show uniformly low signal intensity in the involved bones, whereas increased signal intensity is generally observed in T2-weightedspin echo images. Enhancement of the lesions is usually seen after intravenous administration of gadolinium. ${ }^{7}$

It is important to rule out other conditions through history and meticulous physical examination. Appropriate blood tests and radiographic studies should be done to rule out other common underlying causes of osteolysis such as infection, cancer (primary or metastatic), inflammatory or endocrine disorders. Several therapeutic modalities have been used in the management of Gorham's disease. The non-operative options include radiation therapy, anti-osteoclastic medications (bisphosphonates), and alpha-2b interferon. The operative options include surgical resection, reconstruction using a bone graft, or prosthesis ${ }^{2}$.

Gorham's disease is a rare condition with fewer than 200 cases reported in the literature ${ }^{4}$. Our case was diagnosed incidentally on evaluation for pain abdomen against a background history of chylothorax in the neonatal period, sibling history of osteogenesis imperfecta and typical radiological and histopathological features. This is the first case reported with a disappearing spleen in Gorham's disease on follow-up. The etio-pathogenesis of autosplenctomy seems to be as enigmatous as that of the disease itself. One report on an autopsy study in a case of Gorham's disease revealed significant lymphangiectatic abnormalities of the pleural, peritoneal, diaphragmatic, splenic, and small bowel tissue with lymphangiomatous masses in the thoracic and mediastinal regions suggesting a possible progressive lymphatic dysplasia ${ }^{10}$. Our case could have had similar lesions in the spleen, which could then have undergone auto-splenectomy following progressive loss of tissue.

This case has been brought out to highlight this unusual condition of multicentric Gorham's disease undergoing auto-splenectomy, which has never been reported in literature.

\section{Acknowledgement: None}

Funding: None

Conflict of Interest: None 


\section{References}

1. Gorham LW, Stout AP. Massive Osteolysis (Acute Spontaneous Absorption of Bone, Phantom Bone, Disappearing Bone): It's Relation to Hemangiomatosis. J Bone Joint Surg [Am] 1955; 37-A: 985-1004.

2. Patel D V. Gorham's Disease or Massive Osteolysis. Clin Med \& Res 2005; 3 : 65-74.

3. Lee S, Finn L, Sze RW, Perkins JA, Sie KC. Gorham Stout Syndrome (disappearing bone disease): Two Additional Case Reports and a Review of the Literature. Arch Otolaryngol Head Neck Surg 2003; 129:1340-43.

4. Boyle MJ, Alison P, Taylor G, Lightbourne BA. A Case of Gorham's Disease Complicated by Bilateral Chylothorax. Heart Lung Circ 2007; Sep :e-pub

5. Halliday DR, Dahlin DC, Pugh DG, Young HH. Massive Osteolysis and Angiomatosis. Radiology 1964; 82:637-44.
6. Kery L, Wouters HW. Massive Osteolysis: Report of Two Cases. J Bone Joint Surg [Br] 1970; 52B:452-59.

7. Spieth ME, Greenspan A, Forrester DM, Ansari AN, Kimura RL, Gleason-Jordan I. Gorham's Disease of the Radius: Radiographic, Scintigraphic, and MRI findings with Pathologic Correlation. A Case Report and Review of the Literature. Skeletal Radiol 1997; 26:659-63.

8. Devlin RD, Bone HG 3rd, Roodman GD. Interleukin-6: A Potential Mediator of the Massive Osteolysis in Patients with Gorham-Stout Disease. J Clin Endocrinol Metab1996; :1893-97.

9. Resnick D. Chapter 89. Osteolysis and Chondrolysis. In: Resnick D, ed. Diagnosis of Bone and Joint Disorders. Fourth Edition. Philadelphia, Pennsylvania, USA: W.B.Saunders Company; 2002. Volume 5. pages 4920-4944.

10. Vigorita VJ, Magitsky S, Bryk E. Gorham's Disease: An Autopsy Report. Clin Orthop Relat Res 2006; 451:267-73. 